University of Nebraska - Lincoln

DigitalCommons@University of Nebraska - Lincoln

7-1988

\title{
Focality and Mobility of Some Peridomestic Cockroaches in Florida (Dictyoptera: Blattaria)
}

Richard J. Brenner

Insects Affecting Man and Animals Research Laboratory, USDA-ARS, Gainesville, Florida 32604

Follow this and additional works at: https://digitalcommons.unl.edu/entomologyother

Part of the Entomology Commons

Brenner, Richard J., "Focality and Mobility of Some Peridomestic Cockroaches in Florida (Dictyoptera: Blattaria)" (1988). Entomology Papers from Other Sources. 76.

https://digitalcommons.unl.edu/entomologyother/76

This Article is brought to you for free and open access by the Entomology Collections, Miscellaneous at DigitalCommons@University of Nebraska - Lincoln. It has been accepted for inclusion in Entomology Papers from Other Sources by an authorized administrator of DigitalCommons@University of Nebraska - Lincoln. 


\title{
Focality and Mobility of Some Peridomestic Cockroaches in Florida (Dictyoptera: Blattaria)
}

\author{
RICHARD J. BRENNER
}

Insects Affecting Man and Animals Research Laboratory, USDA-ARS, Gainesville, Florida 32604

\begin{abstract}
Ann. Entomol. Soc. Am. 81(4): 581-592 (1988)
ABSTRACT The microhabitat distribution and activities of peridomestic cockroaches were examined (August to October 1985) at three sites in northcentral Florida to assess concentration, immobility, and accessibility of populations. Smokybrown cockroaches, Periplaneta fuliginosa (Serville), and Eurycotis floridana (Walker) accounted for at least $67 \%$ of cumulative recaptures at each site. Populations were strongly concentrated in palms, trees with treeholes, woodpiles, and (to a lesser extent) various mulches; salient differences were observed for each species, indicating a partitioning of resources. Recapture rates were high, averaging $>62 \%$ over all three sites for females of both species; rates were significantly lower for males $(P<0.05)$, but still averaged $>40 \%$. Mean distances traveled were generally less than $2 \mathrm{~m}$. However, frequency distributions of distances moved per successive recapture were strongly right-skewed, invalidating the mean as an estimate of typical mobility; more than $72 \%$ of 690 recaptures of all stages of both species involved net movement of less than $1 \mathrm{~m}$ (median $=$ 0 ). Daily activity was strongly correlated negatively with change in precipitation and positively with maximal temperatures, but it was best predicted by low temperatures during periods of hot weather. Minimal temperature threshold of activity was about $10^{\circ} \mathrm{C}$. The data indicate that distributions and activity patterns are predictable and suggest that a suppression strategy based on intercepting populations with baited traps or toxic baits would affect control.
\end{abstract}

KEY WORDS Insecta, spatial activity, smokybrown

IN THE SOUTHERN UNITED STATES, invasion of peridomestic cockroaches, those associated with humans in and around the domestic environment, is a common problem to homeowners (Hagenbuch et al. in press). Because reservoirs exist outside the home, the problems will persist unless outdoor populations are suppressed or prevented from entering homes (Fleet et al. 1978, Piper \& Frankie 1978). Some studies have examined population dynamics of these cockroaches (principally the smokybrown cockroach, Periplaneta fuliginosa (Serville)), but these used traps placed in known harborage sites; they were not designed to identify principal reservoirs (Fleet et al. 1978, Appel \& Rust 1985).

A greater understanding of the factors that regulate these cockroaches' microdistribution and survival would help in predicting spatial distribution and rate of population expansion and in developing sound strategies for their suppression. Characterization of several specific behavioral traits that define concentration, mobility, and accessibility of populations is requisite. Thus the first objective of this study was to identify principal foci by determining spatial distribution (i.e., concentration) outside the home. My working hypothesis was that peridomestic cockroaches are concentrated in visually identifiable and accessible foci. Other objectives were to quantify population size and typical mobility patterns of these cockroaches, and to cor- relate activity with meteorological parameters to identify factors that affect behavioral patterns during the season when populations are greatest and most pestiferous.

\section{Materials and Methods}

Three home sites in Gainesville, Fla., were selected for this study, based on their ecological profiles. All of the homes were constructed on slabs and not subject to monthly application of pesticides outdoors. Research was conducted in late summer and early fall, when cockroach populations peak in the Gulf states (Fleet et al. 1978, Appel \& Rust 1985, Hagenbuch et al. in press). Site A (Fig. la) included 0.5 ha of land surrounding a single-story home; baldcypress wood mulch was used exclusively for landscaping. All trees south of the house were cabbage palms, Sabal palmetto (Walt.), and Canary Island date palms, Phoenix canariensis Hort. ex Chabaud, both with smooth trunks. Trees north of the house were a mixture of oaks, Quercus spp.; sweetgum, Liquidambar styraciflua L.; and baldcypress, Taxodium distichum (L.) Rich. Three trees east of the house were pines, Pinus spp. Firewood was stacked $35 \mathrm{~m}$ from the house, and a smaller pile was stored on the concrete patio adjacent to the north side of the house. Trapping, begun on 29 August 1985, was suspended during 

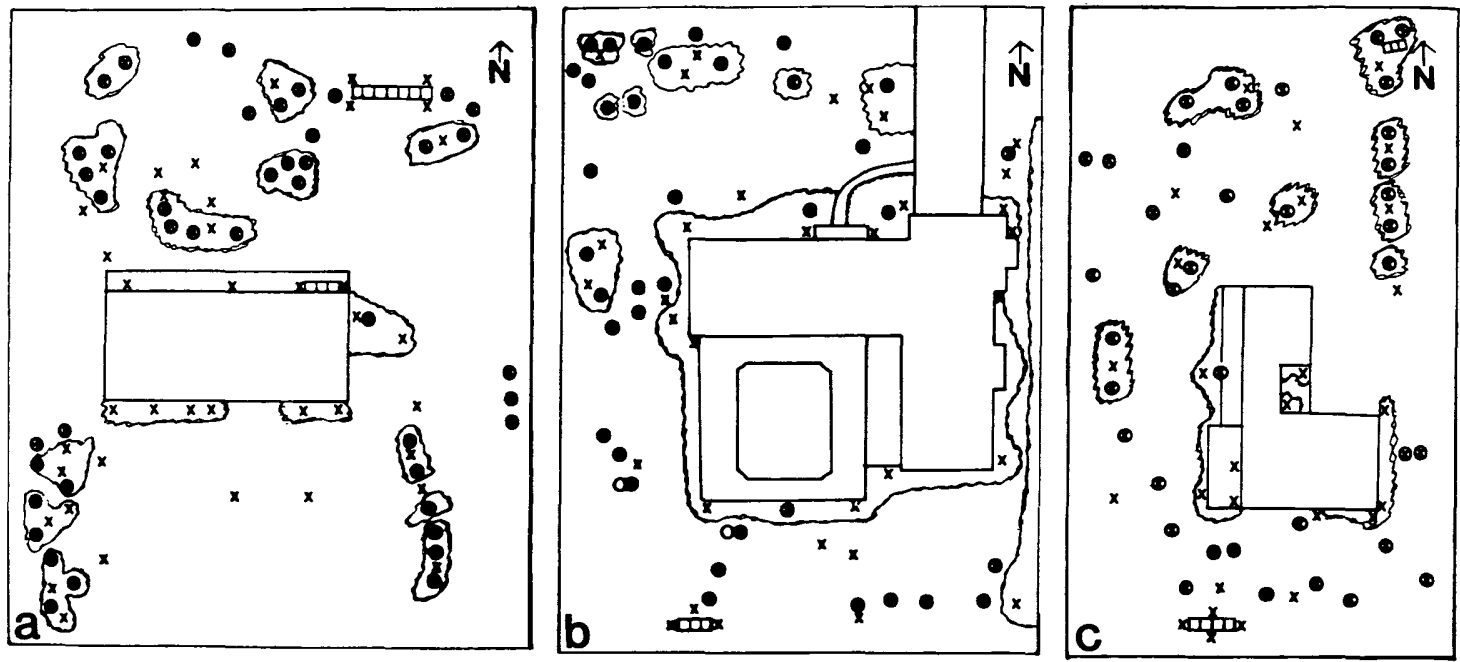

Fig. 1. Schematic representation of sites A (a), B (b), and C (c), showing trees $(O)$, mulch $(\otimes \times \otimes)$, and woodpiles $(\square \square \square \square)$, relative to the house. Marks $(x)$ show trap locations on the ground and at $1.5 \mathrm{~m}$ above the ground on the trunks of trees $(\mathbf{)}$. Ground traps in open areas were in grass.

the effects of hurricane Elena (1-3 September) and continued through 11 September.

Site B (Fig. 1b) included a house on 0.2 ha and was chosen primarily for its variety of mulches: pine needle mulch at the base of the house (north) and in several areas beneath trees, pine bark mulch outside the enclosed swimming pool and on the east and south sides of the house, and deciduous leaf mulch along the east side of the property beneath a long run of bushes. Trees included three palms (cabbage palm, rough bark), and a mix of pines, oaks, sweetgum, and several small fruit trees. One woodpile was $25 \mathrm{~m}$ from the house. Trapping was conducted between 13 September and $4 \mathrm{Oc}-$ tober.

Site C (Fig. 1c) included a home on 0.4 ha; it was selected because of a uniformity of plantings and landscaping. Hardwood trees were predominant-oaks, sweetgums, and hickory, Carya sp. Cypress mulch was used for landscaping around the trees, within the courtyard, on the east side of the house, and around the wooden deck running the extent of the west side. In an area ( 4 by $3 \mathrm{~m}$ ) beneath a small magnolia tree (north of house), leaves were allowed to accumulate, producing the only area of deciduous mulch. Two woodpiles were located $15 \mathrm{~m}$ and $30 \mathrm{~m}$ from the house. Trapping was conducted from 2 to 12 October.

Cockroaches were trapped live in 1-liter lined paint cans greased lightly on the inside upper 3 $\mathrm{cm}$ with a mixture of mineral oil and white petroleum jelly (2:3 ratio). Each trap was baited with about $2 \mathrm{~g}$ of dried distillers' grain (Brenner \& Patterson in press). Traps included a polypropylene canopy to keep out rain; they could be affixed to any vertical surface with Velcro glued to the top outside edge of the can. As needed, traps were cleaned, greased, and rebaited.
All of the ecological zones were sampled-trees, grass, mulch, flower gardens, base of house, and woodpiles. On trees, two opposed traps were placed $1.5 \mathrm{~m}$ above the ground. At sites A, B, and C, 130, 109 , and 103 traps were used, respectively, for totals of 1,300,2,289, and 1,030 trap-days (number of traps times number of days). The mean distance ( \pm SEM) from each trap to the nearest trap was $1.82 \pm 0.08,3.09 \pm 0.22$, and $0.95 \pm 0.06 \mathrm{~m}$ at sites A, B, and C. For these calculations, each tree was considered to have only one trap.

Daily, cockroaches in each trap were narcotized lightly in situ with gaseous $\mathrm{CO}_{2}$, identified, and categorized by size (small, medium, and large nymphs) and sex (large nymphs and adults). All adults and most large and medium nymphs were marked with a water-base colored paint pen (Brenner \& Patterson in press). At sites A and B, marks were unique to each trap site; additional marks were added for each recapture at the same site. This allowed the determination of gross movement and recapture rates, but it did not allow assessment of recapture by time. Therefore, at site $\mathrm{C}$, each cockroach was given a unique series of three colored marks ( 10 colors available) representing a three-digit number (Brenner \& Patterson in press). Having been marked and recorded, the anesthetized cockroaches were then placed adjacent to the ground trap or on top of the canopy on tree traps.

The null hypothesis that peridomestic cockroaches are uniformly distributed was tested against the alternative hypothesis that they are distributed contagiously (i.e., concentrated) in principal foci visually recognizable by microhabitat. Principal foci were defined as those microhabitats with the most cockroaches, and it was assumed that the probability of survival for the population was greatest at these sites. Cumulative numbers of cockroaches (by 
Table 1. Summary of cumulative number of peridomestic cockroaches captured at three sites

\begin{tabular}{|c|c|c|c|c|c|c|c|}
\hline Species & \multicolumn{6}{|c|}{ No. and percentage by site (no. trap-days) } & $\chi^{2 a}$ \\
\hline Eurycotis floridana (Walker) & 74 & 9.9 & 544 & 46.1 & 189 & 26.2 & 294.7 \\
\hline Periplaneta fuliginosa (Serville) & 427 & 56.9 & 321 & 27.2 & 317 & 44.0 & 172.8 \\
\hline (Saussure and Zehntner) & 218 & 29.0 & 288 & 24.4 & 173 & 24.0 & 6.4 \\
\hline Parcoblatta spp. & 12 & 1.6 & 6 & 0.5 & 0 & 0.0 & 14.8 \\
\hline Pycnoscelus surinamensis (L.) & 20 & 2.7 & 18 & 1.5 & 42 & 5.8 & 28.6 \\
\hline Total & 751 & 100.0 & 1,179 & 100.0 & 721 & 100.0 & \\
\hline No. per trap-day & 0.578 & & 0.515 & & 0.700 & & \\
\hline
\end{tabular}

a Refers to a test of the hypothesis that the proportions of each species are equal among sites; $\mathrm{df}=2$, critical value at $P=0.05$ is 5.99 (SAS Institute 1985b).

b Not applicable; insufficient data

species and stage) per trap site were normalized by transformation to ranks (Conover \& Iman 1981, SAS Institute 1985a), and mean ranks per microhabitat were analyzed according to SAS GLM procedures with the Waller-Duncan test used to separate means (SAS Institute 1985b). Trap density was equalized for tree and nontree sites by dividing cumulative number of cockroaches caught in trees by two, because there were two traps per tree.

Population densities were estimated at $1-m$ intervals throughout each study site according to the Kriging method of gridding, which assumes a trend (large-scale variation) and fluctuation (small-scale random process) of distribution (Ripley 1981). A commercially available software package for microcomputers was used to visualize spatial distributions (Golden Graphics Software, Golden, Colo.). Data from all traps within a radius of $20 \mathrm{~m}$ were incorporated into each point estimate of population density. Contours were constructed showing equal density (cumulative numbers per trap for 1,030 trap-days); this allowed visual comparisons among sites. Thus, if populations were patchy and highly concentrated only in certain locations, contours would be centered on these locations and drop off sharply between them; if populations were diffuse, contours would lack well-defined centers and tend to be linear.

Recapture rates were computed by species and stage, as were mean number of times captured, and mean (and median) distance traveled per recapture. These data were used to estimate populations at each site according to several applicable procedures including the Lincoln index, Bailey's modified Lincoln index, the Jolly-Seber stochastic model, and the Schnabel census. All of these procedures are described and discussed by Southwood 1978).

Three meteorological parameters, minimal and maximal temperatures and rainfall, were measured daily at each site approximately $0.5 \mathrm{~m}$ above the ground to assess relevance of each to the activity of cockroaches. To correct for differences among sites in the total number trapped, daily catches were expressed as a proportion of the mean catch calculated for that site. Each parameter was then evaluated in linear regression models in a stepwise manner (SAS Institute 1985b).

\section{Results}

Species Composition. Chi-square analysis of proportions of each species per site indicated that species composition differed among sites (Table 1) $(P<0.05$; SAS Institute 1985b). Smokybrown cockroaches were most common at sites $A$ and $C$, whereas E. floridana predominated at site B. Cariblatta lutea lutea (Saussure \& Zehntner) accounted for approximately $25 \%$ of collections at each site. Other species constituted less than $6 \%$ of the cumulative catches. Because smokybrown cockroaches and E. floridana were most abundant and commonly are considered the most pestiferous species in this area, the remainder of this paper focuses on these species.

Although there is a trend for higher nymphal proportions of smokybrown populations than of $E$. floridana, based on daily cumulative captures per site, differences were significant only at site $\mathrm{B}(F=$ $7.42 ; \mathrm{df}=1,39 ; P=0.01)$. Proportions of smokybrown cockroaches were $0.56,0.47$, and 0.43 for sites $\mathrm{A}, \mathrm{B}$, and $\mathrm{C}$, respectively, and were not significantly different $(F=2.36 ; \mathrm{df}=2,35 ; P=0.11)$ among sites; proportions of E. floridana ( 0.45 at A, 0.34 at $\mathrm{B}$, and 0.34 at $\mathrm{C}$ ) also did not differ among sites $(F=1.59 ; \mathrm{df}=2,36 ; P=0.22)$.

Recapture rates were significantly higher for females of both species, except smokybrowns at site $A$, and $E$. floridana at site $C$, where the differences were not significant (based on $95 \%$ confidence intervals of the binomial proportion) (Table 2). Mean number of times captured ranged from 1.00 (site C, smokybrown small nymphs) to 2.33 (site B, smokybrown females), with a mean total of 1.70 over all sites, species, and stages. Females account- 
Table 2. Summary of number of cockroaches marked by number of times captured

\begin{tabular}{|c|c|c|c|c|c|c|c|c|c|c|c|c|c|}
\hline \multirow{2}{*}{ Site } & \multirow{2}{*}{ Species } & \multirow{2}{*}{ Stage } & \multirow{2}{*}{$\begin{array}{c}\text { Total } \\
\text { no. } \\
\text { marked }\end{array}$} & \multicolumn{8}{|c|}{ No. times captured ${ }^{a}$} & \multicolumn{2}{|c|}{ Recapture } \\
\hline & & & & 1 & 2 & 3 & 4 & 5 & 6 & Mean & $\mathrm{SE}$ & $\%$ & $95 \% \mathrm{CL}$ \\
\hline \multirow{8}{*}{$\mathrm{A}$} & & $\delta \hat{z}$ & 72 & 45 & 10 & 13 & 2 & 2 & 0 & 1.69 & 0.12 & 37.5 & $26.3-48.7$ \\
\hline & & Large nymphs & 69 & 43 & 18 & 5 & 3 & $\overline{0}$ & 0 & 1.54 & 0.10 & 37.7 & $26.3-49.1$ \\
\hline & & Medium-size nymphs & 78 & 64 & 10 & 0 & 4 & 0 & 0 & 1.28 & 0.08 & 17.9 & $9.5-26.3$ \\
\hline & & Small nymphs & 16 & 15 & 1 & 0 & 0 & 0 & 0 & 1.06 & 0.06 & 6.3 & $-5.7-18.3$ \\
\hline & & రิổ & 10 & 6 & 1 & 3 & 0 & 0 & 0 & 1.70 & 0.30 & 40.0 & $9.6-70.4$ \\
\hline & & Large nymphs & 9 & 3 & 2 & 4 & 0 & 0 & 0 & 2.11 & 0.31 & 66.7 & $35.9-97.5$ \\
\hline & & Medium-size nymphs & 9 & 7 & 2 & 0 & 0 & 0 & 0 & 1.22 & 0.15 & 22.2 & $-5.0-49.4$ \\
\hline & Total & & 320 & 210 & 60 & 33 & 15 & 2 & 0 & 1.56 & 0.05 & 34.4 & $29.3-39.5$ \\
\hline \multirow[t]{7}{*}{$\mathrm{B}$} & P. fuliginosa & $\wp$ & 43 & 11 & 15 & 9 & 8 & 0 & 0 & 2.33 & 0.16 & 74.4 & $61.3-87.5$ \\
\hline & & ofं & 42 & 25 & 5 & 10 & 1 & 1 & 0 & 1.76 & 0.16 & 40.5 & $25.6-55.4$ \\
\hline & & $\delta 8$ & 98 & 50 & 11 & 24 & 11 & 2 & 0 & 2.02 & 0.12 & 49.0 & $39.2-58.8$ \\
\hline & & Large nymphs & 11 & 6 & 2 & 3 & 0 & 0 & 0 & 1.73 & 0.29 & 45.5 & $16.1-74.9$ \\
\hline & & Medium-size nymphs & 78 & 45 & 25 & 7 & 1 & 0 & 0 & 1.54 & 0.11 & 42.3 & $31.3-53.3$ \\
\hline & & Small nymphs & 40 & 30 & 9 & 1 & 0 & 0 & 0 & 1.28 & 0.17 & 25.0 & $11.7-38.3$ \\
\hline & Total & & 482 & 255 & 114 & 80 & 28 & 4 & 0 & 1.77 & 0.12 & 47.1 & $42.2-51.2$ \\
\hline \multirow[t]{6}{*}{$\mathrm{C}$} & P. fuliginosa & $\wp q$ & 54 & 19 & 16 & 12 & 3 & 3 & 1 & 2.22 & 0.17 & 64.8 & $52.1-77.5$ \\
\hline & & $\delta \hat{\theta}$ & 33 & 19 & 4 & 5 & 3 & 2 & 0 & 1.94 & 0.23 & 42.4 & $25.5-59.3$ \\
\hline & & Large $q$ nymphs & 9 & 3 & 3 & 2 & 1 & 0 & 0 & 2.11 & 0.35 & 66.7 & $35.9-97.5$ \\
\hline & & Large $\delta$ nymphs & 22 & 13 & 5 & 4 & 0 & 0 & 0 & 1.59 & 0.17 & 40.9 & $20.3-61.5$ \\
\hline & & Medium-size nymphs & 43 & 26 & 11 & 6 & 0 & 0 & 0 & 1.53 & 0.11 & 39.5 & $24.8-54.2$ \\
\hline & & Small nymphs & 13 & 13 & 0 & 0 & 0 & 0 & 0 & 1.00 & 0.00 & 0.0 & - \\
\hline
\end{tabular}

${ }^{a}$ Those listed as having been captured once were never recaptured, those captured twice were recaptured once, etc.

ed for 40,50 , and $62 \%$ of smokybrown adults at sites $\mathrm{A}, \mathrm{B}$, and $\mathrm{C}$, respectively.

Focality. The null hypothesis of a uniform distribution of cockroaches was rejected for all three sites (values for total smokybrown and E. floridana for site A: $F=14.5$; $\mathrm{df}=9,74 ; P<0.0001$; site B: $F=7.14$; df $=10,58 ; P<0.0001$; site C: $F=$
9.22, $\mathrm{df}=6,59 ; P<0.0001)$. Thus, data were separated by stage and species to determine which microhabitats have significantly higher cockroach densities.

At site A, smokybrown nymphs and adults were most abundant in palm and oak trees, followed by baldcypress trees and woodpiles (Table 3; Fig. 2).

Table 3. Comparison of mean cumulative number of cockroaches per trap by microhabitat at site $A$

\begin{tabular}{|c|c|c|c|c|c|c|c|c|c|}
\hline \multirow{2}{*}{ Microhabitat } & \multicolumn{4}{|c|}{ P. fuliginosa } & \multicolumn{3}{|c|}{ E. floridana } & \multirow{2}{*}{ Total $^{a}$} & \multirow{2}{*}{$\begin{array}{l}\text { Cariblatta } \\
\text { lutea lutea }\end{array}$} \\
\hline & $n$ & Nymphs & Adults & Total & Nymphs & Adults & Total & & \\
\hline Grass & 11 & $0.0 \mathrm{c}$ & $0.0 \mathrm{e}$ & $0.0 f$ & $0.0 \mathrm{~b}$ & $0.0 \mathrm{~b}$ & $0.0 \mathrm{c}$ & $0.0 \mathrm{e}$ & $0.6 \mathrm{c}$ \\
\hline House & 4 & $0.3 \mathrm{bc}$ & $0.3 \mathrm{de}$ & $0.5 \mathrm{def}$ & $0.3 \mathrm{~b}$ & $0.0 \mathrm{~b}$ & $0.3 \mathrm{bc}$ & $0.8 \mathrm{~cd}$ & $0.5 c$ \\
\hline Woodpile & 4 & $1.5 \mathrm{a}$ & $0.0 \mathrm{e}$ & $1.5 \mathrm{abc}$ & $0.5 \mathrm{~b}$ & $2.5 \mathrm{a}$ & $3.0 \mathrm{ab}$ & $4.5 \mathrm{ab}$ & $2.3 \mathrm{abc}$ \\
\hline Cypress mulch & 14 & $0.1 \mathrm{bc}$ & $0.1 \mathrm{e}$ & $0.3 \mathrm{ef}$ & $0.0 \mathrm{~b}$ & $0.0 \mathrm{~b}$ & $0.0 \mathrm{c}$ & $0.3 \mathrm{e}$ & $8.0 \mathrm{ab}$ \\
\hline House/mulch & 7 & $0.9 \mathrm{bc}$ & $0.9 \mathrm{cde}$ & $1.7 \mathrm{cde}$ & $0.1 \mathrm{~b}$ & $0.0 \mathrm{~b}$ & $0.1 \mathrm{bc}$ & $1.9 \mathrm{~cd}$ & $0.7 \mathrm{bc}$ \\
\hline Baldcypress trees & 4 & $2.2 \mathrm{a}$ & $0.9 \mathrm{abc}$ & $3.0 \mathrm{ab}$ & $1.3 \mathrm{a}$ & $0.1 \mathrm{ab}$ & $1.4 \mathrm{a}$ & $4.4 \mathrm{ab}$ & $1.6 a b c$ \\
\hline Oak trees & 9 & $3.3 \mathrm{a}$ & $2.4 \mathrm{ab}$ & $5.7 \mathrm{a}$ & $0.4 \mathrm{~b}$ & $0.6 \mathrm{ab}$ & $1.0 \mathrm{abc}$ & $6.7 \mathrm{a}$ & $0.5 \mathrm{bc}$ \\
\hline Pine trees & 3 & $0.3 \mathrm{bc}$ & $0.0 \mathrm{e}$ & $0.3 \mathrm{def}$ & $0.0 \mathrm{~b}$ & $0.0 \mathrm{~b}$ & $0.0 \mathrm{c}$ & $0.3 \mathrm{de}$ & $3.5 \mathrm{a}$ \\
\hline Palm trees & 16 & $3.3 \mathrm{a}$ & $4.2 \mathrm{a}$ & $7.5 \mathrm{a}$ & $0.2 \mathrm{~b}$ & $0.3 \mathrm{ab}$ & $0.4 \mathrm{bc}$ & $7.9 \mathrm{a}$ & $0.2 \mathrm{c}$ \\
\hline Sweetgum trees & 13 & $0.9 \mathrm{ab}$ & $0.4 \mathrm{bcd}$ & $1.4 \mathrm{bcd}$ & $0.2 \mathrm{~b}$ & $0.5 \mathrm{ab}$ & $0.7 \mathrm{bc}$ & $2.0 \mathrm{bc}$ & $1.4 \mathrm{abc}$ \\
\hline
\end{tabular}

Means in the same column followed by the same letter are not significantly different $(P<0.01, \mathrm{df}=75$, Waller-Duncan test applied to mean ranks). Significance for Florida wood cockroach nymphs and adults is at the $2.5 \%$ level.

${ }^{a}$ Total of all smokybrown and E. floridana. 
Although numbers of $E$. floridana were small, adults were most abundant in woodpiles and trees, whereas nymphs were most abundant in baldcypress trees. Neither species was captured commonly in grass or in cypress mulch; of 751 cumulative cockroaches captured at this site, only $14(1.9 \%)$ were taken in mulch at the base of the house. C. lutea lutea was captured in highest numbers in cypress mulch.

At site B, smokybrown nymphs were most abundant in the decaying woodpile, and least in areas of deciduous leaf mulch (Table 4; Fig. 3). Smokybrown adults were most abundant in palm trees, the woodpile, beds of canna and banana, fruit trees, and pine needle mulch. In contrast with site A, smokybrown cockroaches were not common in oak or sweetgum trees. E. floridana predominated at site $B$, where they were most abundant in canna and banana beds (nymphs and adults) and the woodpile (adults). Populations also were relatively high in all three types of mulch. As at site A, C. lutea lutea was most abundant in mulches.

Results from site $\mathrm{C}$ paralleled those from site A (Table 5; Fig. 4). Trees (mostly oaks) and woodpiles clearly served as principal foci for smokybrown and $E$. floridana; C. lutea lutea was most abundant in mulches and thick growth of St. Augustine grass. Data from trees were segregated further as to presence or absence of treeholes (any size), and presence clearly was predictive for the distribution of these larger species. Other parameters, such as tree diameter, did not correlate with the occurrence of cockroaches in trees $(n=36, r=0.1, P>0.05)$.

These focalized populations of peridomestic cockroaches at sites $\mathrm{A}$ and $\mathrm{C}$ are largely arboreal (compare Fig. 2e with 2f, and Fig. 4e with 4f). Because treeholes at site $\mathrm{C}$ were predictive for populations, sites $A$ and $B$ were revisited to examine trees. At site B, only one tree had a small treehole, but four were found at site $A$. Therefore, data from site A were reanalyzed after grouping cumulative number of smokybrown and E. floridana per tree site by presence or absence of treeholes; palm trees were retained as a separate category. Means for palm trees (16.9, $n=15$ trees) and hardwoods with treeholes $(22.5, n=4$ trees) were not significantly different $(P>0.05)$, but differed from means for hardwoods without treeholes $(4.8, n=25$ trees, three species), confirming that these cockroaches are concentrated in trees with treeholes, regardless of the tree species.

Vertical stratification was less evident at site B, where treeholes were uncommon (compare Fig. 3e with 3f). The extensive use of landscaping mulches (other than cypress) that apparently are conducive to safe harborage of peridomestic cockroaches resulted in a diffuse distribution throughout the property, ultimately encroaching on the house.

Mobility. In general, the mean net distances traveled between recaptures were less than $2 \mathrm{~m}$ (Table 6). Among sites, there were no significant differences in mean distances traveled per recapture for smokybrown females or males, nor for $E$.

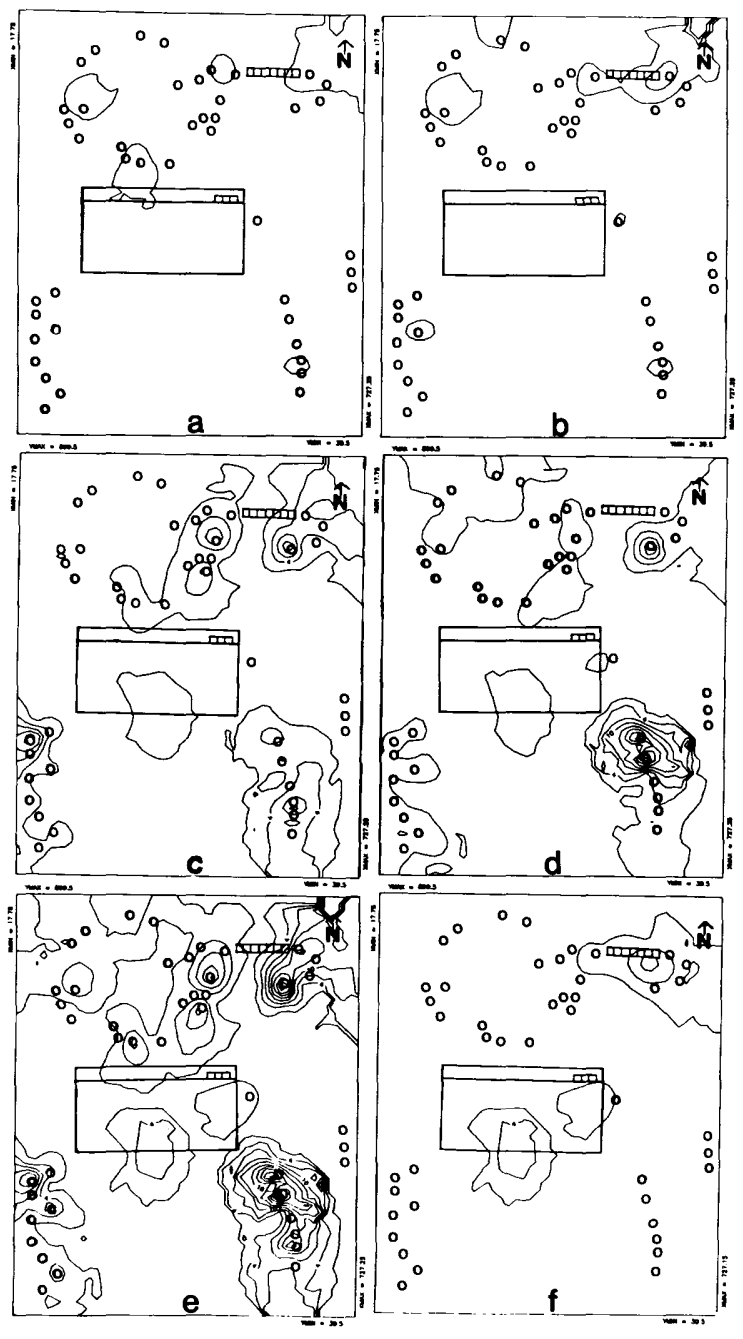

Fig. 2. Spatial distribution at site A of Florida wood cockroach nymphs (a) and adults (b), and smokybrown nymphs (c) and adults (d) relative to the house, trees, and woodpiles. Distributions of both species based on all traps (e) and only ground traps (f) show vertical stratification of habitats. See Fig. la for location of traps. Contours are in intervals of 3 and represent equal cockroach density of cumulative number trapped.

floridana females, males, or large nymphs; this indicated rather uniform behavior for these species at all sites. However, lack of significant differences among sites for E. floridana may be due in part to small numbers available at sites $\mathrm{A}$ and $\mathrm{C}$. There was a general trend for higher means for both females and males at site B, probably because of the more diffuse distribution in mulch. This would suggest that these stages are likely to find acceptable harborage anywhere within this kind of mulch. Consequently, mean distances traveled per recapture would be higher. At site A among smokybrown cockroaches, large nymphs were most mobile, but this trend was not apparent at the other two sites. 
Table 4. Comparison of mean cumulative number of cockroaches per trap by microhabitat at site $B$

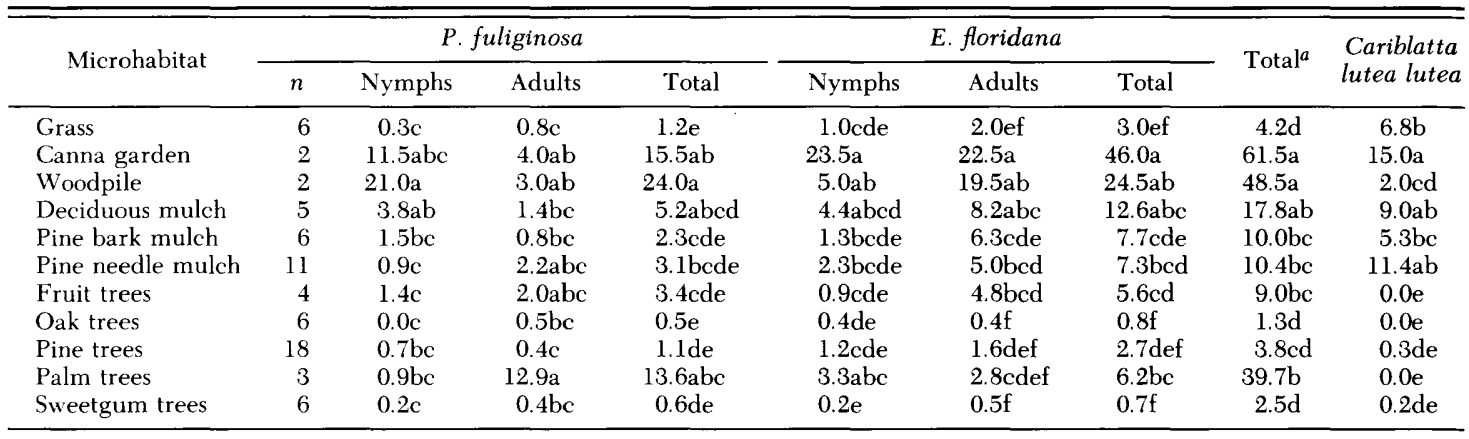

Means in the same column followed by the same letter are not significantly different $(P<0.01$, df $=75$, Waller-Duncan test applied to mean ranks)

${ }^{a}$ Total of all smokybrown and E. floridana.

These data erroneously suggest that individual cockroaches move on average between $20 \mathrm{~cm}$ and almost $6 \mathrm{~m}$ between captures; the use of means rather than medians is deceptive. Frequency distributions for distance traveled in the interval between captures were skewed strongly, invalidating the mean as an appropriate estimate of typical mobility (Fig. 5). For all stages of both species, more than $73 \%$ (501) of 690 recaptures involved net movement of $<1 \mathrm{~m}$. Thus, the median distance traveled was $0 \mathrm{~m}$, and only $20 \%$ of movements involved distances $>2 \mathrm{~m}$.

To test the likelihood that tree traps greatly restrict normal movement of the cockroaches, simple tests were conducted at sites $\mathrm{A}$ and $\mathrm{C}$. At site A, traps in two palms $2 \mathrm{~m}$ apart captured 94 cockroaches during the 10-d study, whereas none was captured in a ground trap directly between the trees. At the conclusion of the study, tree traps were removed and trapping was continued for an additional $5 \mathrm{~d}$. During that time, temperatures and rainfall were similar to those of the previous $10 \mathrm{~d}$. However, only two cockroaches were captured in the ground trap; each had been marked previously at the trees. At site $\mathrm{C}$, traps in two oak trees about $1 \mathrm{~m}$ apart caught 60 cockroaches in $10 \mathrm{~d}$; no ground trap was placed between them. Traps were removed from the trees and 12 others were placed on the ground $0.5 \mathrm{~m}$ apart and $<0.5 \mathrm{~m}$ from the base of the trees in a pattern encircling the two trees. During the next $5 \mathrm{~d}, 11$ cockroaches were captured; all had been marked previously at these trees, and the cockroaches were captured only in the three traps between the trees.

Population Estimates. Two or more methods were used to estimate population sizes from markrelease-recapture data to compare sites. Lincoln indexes were computed for each site, beginning on the fourth day of trapping. Analysis of mean estimates indicated that the populations were significantly larger at sites A and B (Table 7). At site C, populations were estimated using Bailey's modified Lincoln index, and the Jolly-Seber stochastic model. Estimates were compared with the Lincoln index and found not to differ significantly, although they were higher.

An alternative method of estimating populations, known as the Schnabel census, is based on the relationship of the frequency distribution of recaptures (Southwood 1978). Briefly, if a strong linear relationship exists between the log number of cockroaches and the number of times captured, then the regression equation can be used to estimate the number of cockroaches that were never captured. Therefore, the sum of all the categories provides an estimate of the population. Regression equations fit the data remarkably well (Table 8); $r^{2}$ values exceeded 0.94 for all three sites (corre-

Table 5. Comparison of mean cumulative number of cockroaches per trap by microhabitat at site $\mathrm{C}$

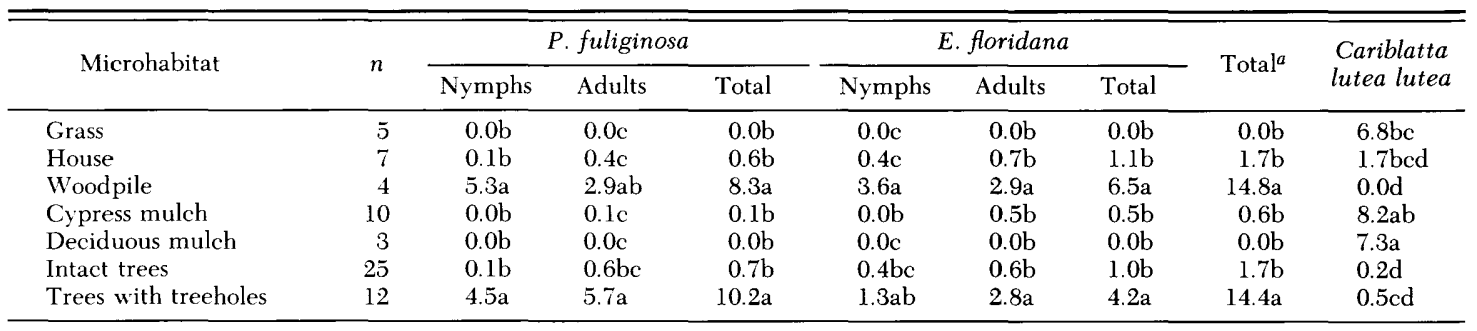

Means in the same column followed by the same letter are not significantly different $(P<0.01$, df $=75$, Waller-Duncan test applied to mean ranks).

${ }^{a}$ Total of all smokybrown and E. floridana. 


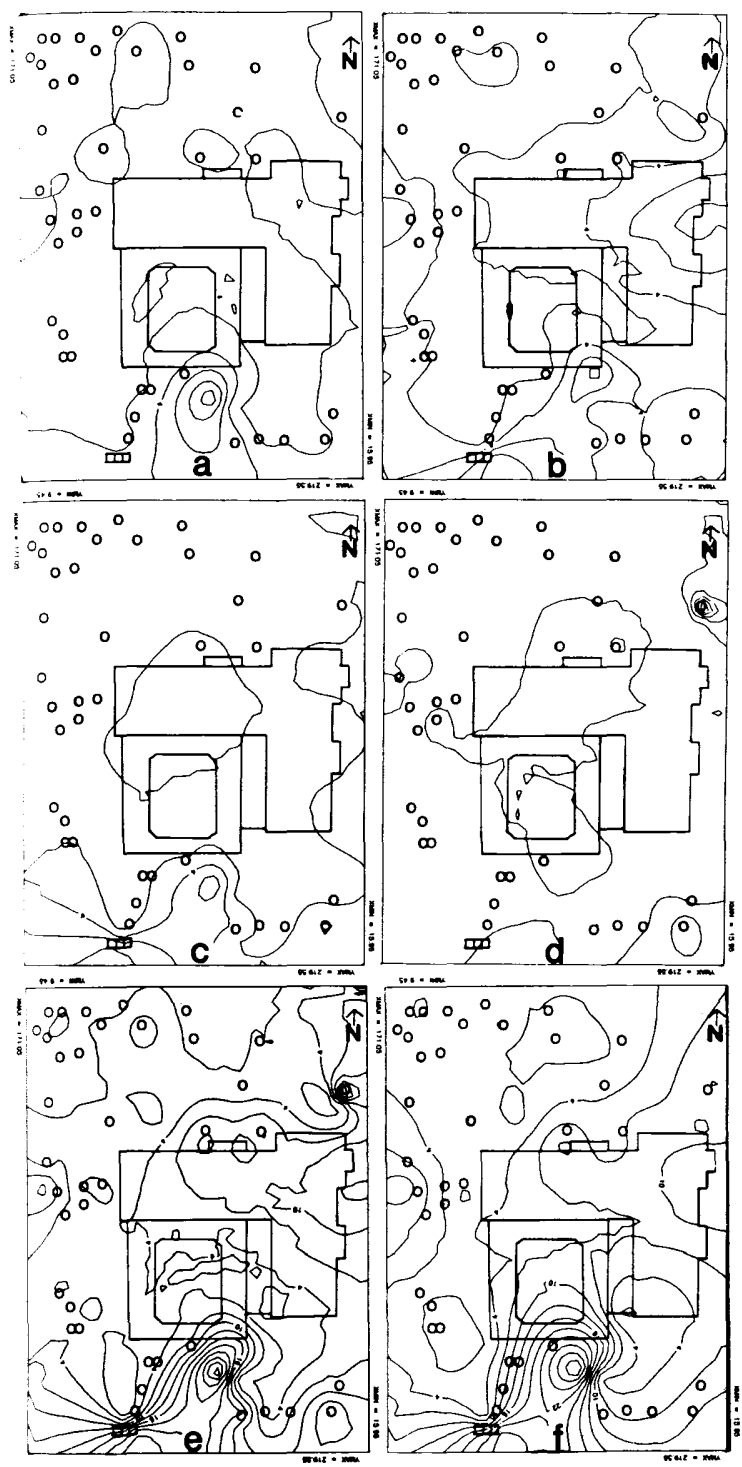

Fig. 3. Spatial distribution at site B of Florida wood cockroach nymphs (a) and adults (b), and smokybrown nymphs (c) and adults (d) relative to house, trees, and woodpile. Distributions of both species based on all traps (e) and only ground traps (f) show significance of mulches. See Fig. lb for location of traps. Contours are in intervals of 3 and represent equal cockroach density of cumulative number trapped.

lation coefficient, $r=0.97$ ). Therefore, the estimate for zero captures and the subsequent population estimate should be reliable. However, estimates were 2-4 times greater than those based on other methods (see Table 7).

Meteorological Factors. Daily precipitation means of $5.00,4.09$, and $3.31 \mathrm{~mm}$ (sites A, B, and C) were not significantly different $(P>0.05$, Waller-Duncan test for SAS GLM procedures). There were differences among sites for temperatures. The mean minimal temperature at site $\mathrm{A}\left(21.4^{\circ} \mathrm{C}\right)$ was
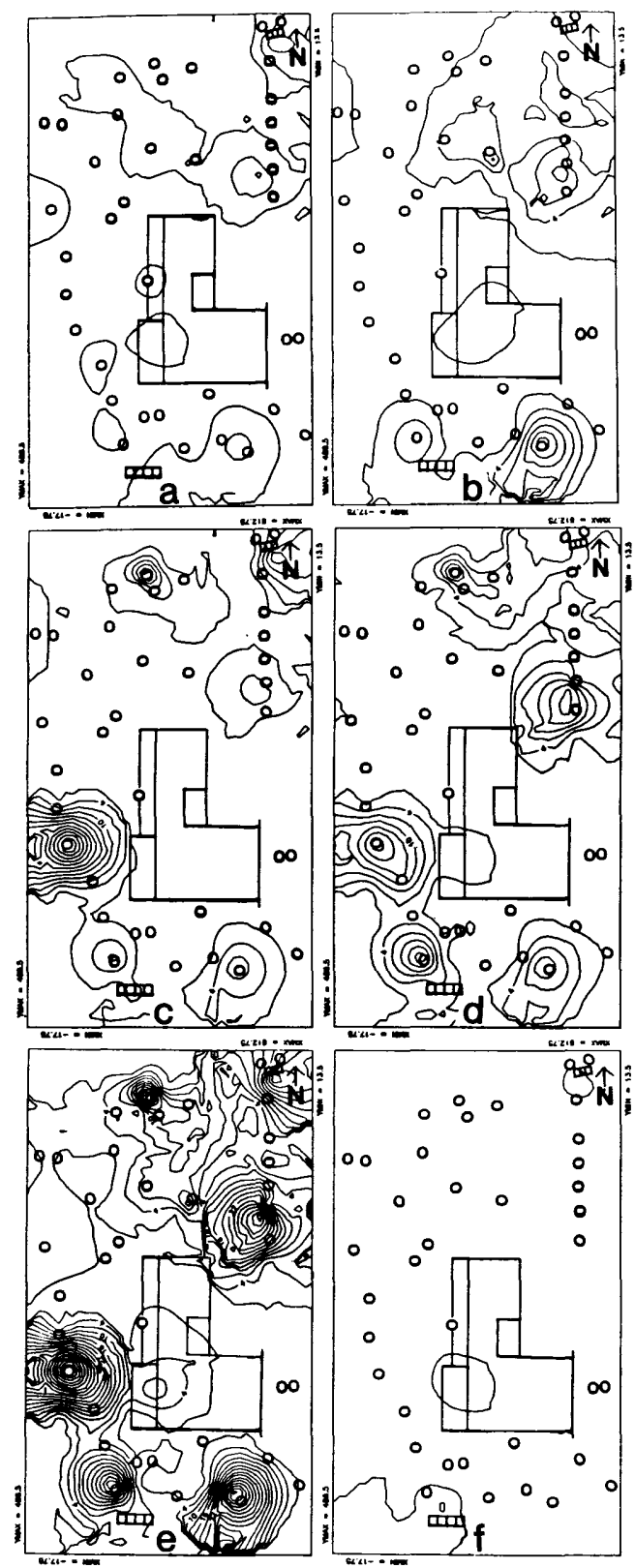

Fig. 4. Spatial distribution at site $\mathrm{C}$ of Florida wood cockroach nymphs (a) and adults (b), and smokybrown nymphs (c) and adults (d) relative to the house, trees, and woodpiles. Distribution of both species based on all traps (e) and only ground traps (f) show a limited terrestrial population. See Fig. 1c for location of traps. Contours are in intervals of 3 and represent equal cockroach density of cumulative number trapped.

significantly higher than at sites $\mathrm{B}$ and $\mathrm{C}$ (19.9 and $17.6^{\circ} \mathrm{C} ; P<0.05$, Waller-Duncan test for SAS GLM procedures), as were mean maximal temperatures $\left(37.1,33.4\right.$, and $34.0^{\circ} \mathrm{C}$ for sites $\mathrm{A}, \mathrm{B}$, and $\left.\mathrm{C}\right)$. Therefore, to minimize their effects (but not eliminate them), daily maximal and minimal temperatures 
Table 6. Mobility of peridomestic cockroaches based on mark-release-recapture studies

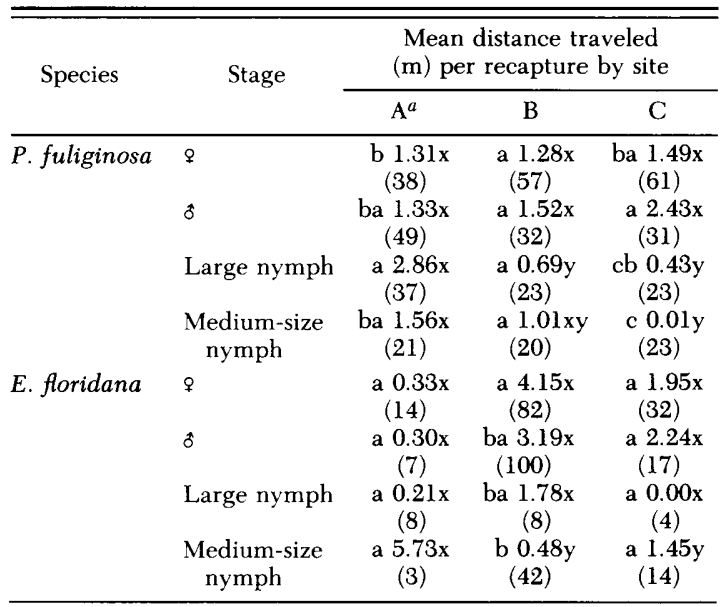

Numbers of observations are in parentheses. All comparisons were made according to the Waller-Duncan test for SAS GLM procedures applied to data transformed to ranks. Means in the same column pertaining to the same species preceded by the same letter $(\mathrm{a}, \mathrm{b}$, or $\mathrm{c})$ are not significantly different $(P>0.05)$. Means in the same row followed by the same letter ( $x$ or $y$ ) are not significantly different $(P>0.05)$.

${ }^{a}$ For comparison of smokybrown stages, differences are significant at $P=0.075(F=2.34, \mathrm{df}=3,141)$, but not at $P=0.05$.
Table 7. Summary of population estimates for total cockroaches (smokybrown and $E$. floridana) by site

\begin{tabular}{llrcc}
\hline Site & Method & $n$ & $\begin{array}{c}\text { Population } \\
\text { estimate }^{a}\end{array}$ & SEM \\
\hline A & Lincoln index & 10 & $497.7 \mathrm{a}$ & 37.2 \\
B & Lincoln index & 11 & $512.3 \mathrm{a}$ & 28.3 \\
C & Lincoln index & 7 & $363.9 \mathrm{~b}$ & 17.3 \\
& Bailey's index & 7 & 445.5 & 40.1 \\
& Jolly-Seber & 7 & $\mathbf{4 6 0 . 3}$ & 53.9 \\
\hline
\end{tabular}

${ }^{a}$ Means for Lincoln index followed by the same letter are not significantly different $(P>0.05$, Waller-Duncan test for SAS GLM procedures). Means for all three methods at site $\mathrm{C}$ are not significantly different $(\mathrm{F}=1.62 ; \mathrm{df}=2,19 ; P=0.225$ ).

per site were expressed as deviations from the pooled minimum and maximum means. Pearson productmoment correlations (SAS Institute 1985b) were computed for precipitation and number of cockroaches trapped. Although precipitation correlated significantly $(r=-0.30, P=0.05)$, a stronger correlation was obtained $(r=-0.54, P=0.0003)$ when rainfall was expressed as the change in precipitation from one day to the next (e.g., day 1 - day $2=$ change in precipitation for day 2 ). This variable was used in the stepwise regression analyses.

At two of the three sites, and for all data, activity of peridomestic cockroaches was best described by

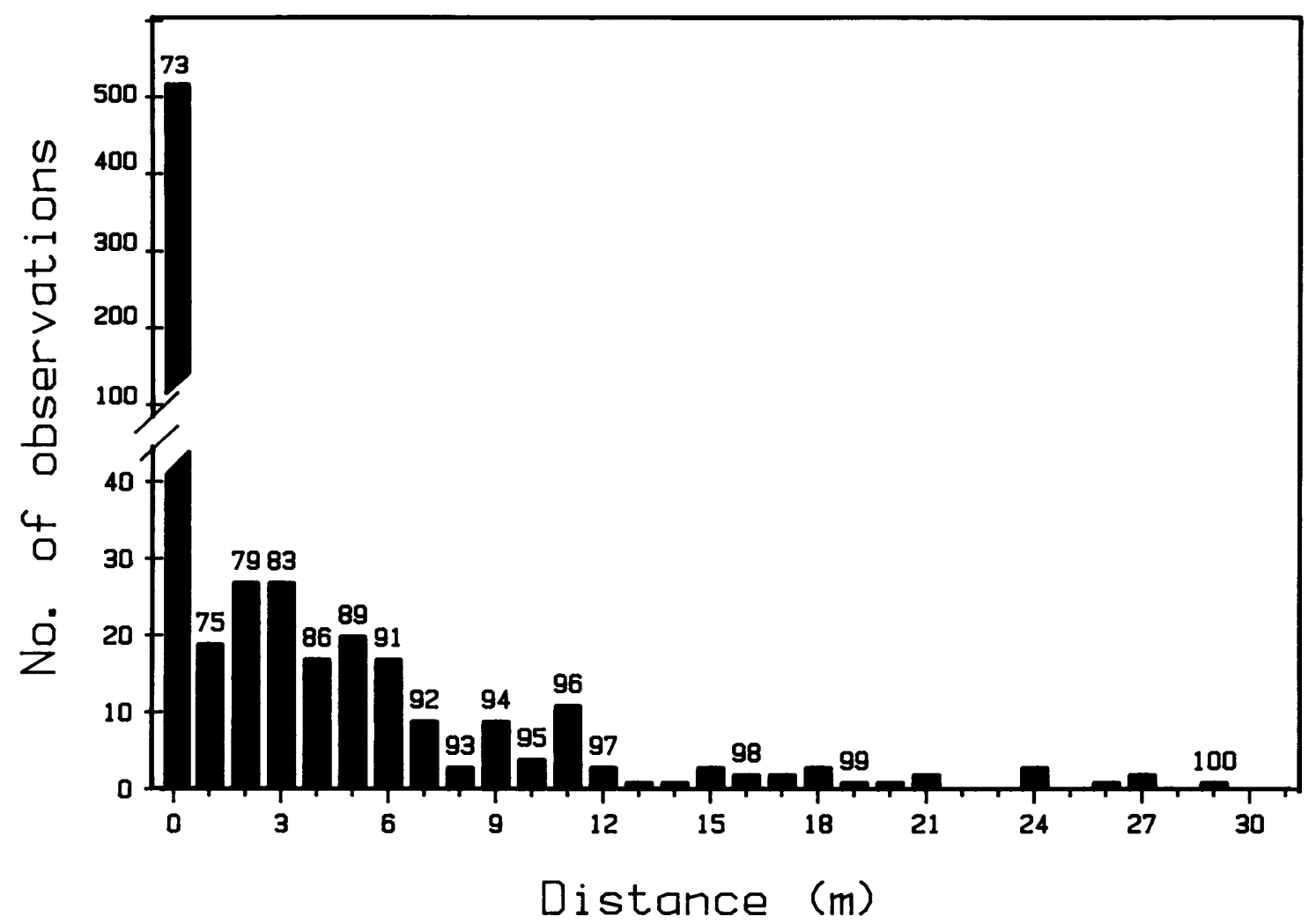

Fig. 5. Frequency distribution for net distance moved between successive recaptures for smokybrown and $E$. floridana cockroaches, pooled over three sites in northcentral Florida. Numbers above bars reflect cumulative percent recapture. 
Table 8. Summary of population estimates based on the Schnabel census ${ }^{a}$

\begin{tabular}{|c|c|c|c|c|c|}
\hline Site & Regression equation & SE of Y estimate & $r^{2}$ & $\begin{array}{c}\text { Population } \\
\text { estimate }\end{array}$ & $95 \% \mathrm{CI}$ \\
\hline $\mathrm{A}$ & $\log \mathrm{Y}=2.81-0.464 \mathrm{X}$ & 0.188 & 0.952 & 988 & $422-2,313$ \\
\hline $\mathrm{C}^{b}$ & $\log \mathrm{Y}=2.75-0.432 \mathrm{X}$ & 0.144 & 0.975 & 883 & $460-1,695$ \\
\hline $\mathrm{C}^{c}$ & $\log \mathrm{Y}=2.46-0.374 \mathrm{X}$ & 0.199 & 0.939 & 495 & $202-1,217$ \\
\hline $\mathrm{C}^{d}$ & $\log \mathrm{Y}=1.88-0.281 \mathrm{X}$ & 0.148 & 0.939 & 159 & $81-310$ \\
\hline
\end{tabular}

${ }^{a}$ See Southwood (1978); data from which regression equations were derived can be found in Table 2 as total values by site. $\mathrm{Y}$ number of cockroaches; $\mathrm{X}$, number of times captured.

${ }^{b}$ Based on all marked cockroaches (289).

${ }^{c}$ Based on those marked during the first $3 \mathrm{~d}$ (184) and recaptured during the remainder of the study.

${ }^{d}$ Based on those marked during the first day only (77) and recaptured during the remainder of the study.

change in precipitation (Table 9), i.e., on days following rainfall, activity was greatest. Observations suggested that this was especially true if rainfall occurred late in the evening and precluded the normal period of activity for that day. At site A, a regression model combining rainfall and minimal temperatures accounted for $68 \%$ of the variability in numbers captured. At site $\mathrm{B}$, the combined influence of rainfall, and maximal and minimal temperatures, accounted for $60 \%$ of the variability. However, at site $\mathrm{C}$, maximal temperatures alone were highly correlated with cockroach activity and explained more than $75 \%$ of the variability among daily numbers captured.

A plot of the relationships of precipitation, temperatures, and total number of cockroaches trapped at site $\mathrm{C}$ revealed a decline of activity as minimal temperatures dropped below $15^{\circ} \mathrm{C}$, and virtual cessation when the minimal temperature was $10.5^{\circ} \mathrm{C}$ (Fig. 6). The lack of rainfall recorded on day 6 (rainfall during the preceding $24 \mathrm{~h}$ ) should have signified an increase in activity. However, presumably because of the low temperature, activity was at a minimum, indicating that $10.5^{\circ} \mathrm{C}$ is at or below the thermal threshold of activity. This dramatic decrease in activity as temperatures dropped below $15^{\circ} \mathrm{C}$ resulted in a nonlinear relationship between minimal temperature and activity. Thus, in the analyses of linear regressions, minimal temperature was not predictive for number of cockroaches trapped (Table 9).

\section{Discussion}

Species compositions differed from those reported by Hagenbuch et al. (in press), in which smokybrown cockroaches constituted only $14 \%$ of total catch. However, in their study, only eight traps were placed at each home, and only at the perimeter of homes. Thus, their protocol probably failed to sample near principal habitats of this species. Nymphal proportions of all species were only $26.5 \%$, also supporting the contention that trap placement biased composition. Nymphal proportions reported here compare favorably with those of Fleet et al. (1978), but they are below those reported by Appel \& Rust (1985) for smokybrowns $(75 \%)$. Differences may be due in part to trap de- sign (straight-sided can with a right angle lip compared with curved inner lip of glass) or bait (distillers' grain compared with Purina cat chow), which may affect escape or attractiveness.

This study has revealed that behavior, including spatial distribution profiles, typical mobility patterns, and periods of activity are predictable for these cockroaches. Data from these three sites clearly show that smokybrown and E. floridana are concentrated in principal foci that can be identified visually by microhabitat. Woodpiles characteristically were infested and they have been shown to harbor significant numbers of cockroaches (Fleet et al. 1978, Appel \& Rust 1985). However, smokybrowns are largely arboreal in their principal foci.

This is the first study to demonstrate and quantify the significance of treeholes. Beatson \& Dripps (1972) found oriental cockroaches (Blatta orientalis L.) outdoors at three sites in England. Although they drew no conclusions concerning focality, their observations indicate an association with trees at two sites. Appel \& Rust (1985) did not sample above ground level, however, they noted that smokybrown nymphs were more abundant at the base of trees in a Texas study site. Other researchers have noted a vertical stratification of sexes on trees, presumably during foraging or mate-seeking, and have observed adult and nymphal cockroaches ascending trees (Schal et al. 1984, Appel

Table 9. Effects of change in precipitation (from the preceding day), daily maximum, and daily minimum temperatures regressed on number of cockroaches trapped per day, expressed as a proportion of the mean number per day per site

\begin{tabular}{|c|c|c|c|c|}
\hline \multirow{2}{*}{ Site } & \multirow{2}{*}{ Variable } & \multicolumn{2}{|c|}{$r^{2}$} & \multirow{2}{*}{$P>F$} \\
\hline & & Partial & Model & \\
\hline \multirow[t]{2}{*}{$\mathrm{A}$} & Rainfall & 0.461 & 0.461 & 0.045 \\
\hline & Min & 0.221 & 0.681 & 0.088 \\
\hline \multirow[t]{3}{*}{ B } & Rainfall & 0.373 & 0.373 & 0.003 \\
\hline & $\operatorname{Max}$ & 0.140 & 0.512 & 0.031 \\
\hline & Min & 0.089 & 0.600 & 0.061 \\
\hline $\mathrm{C}$ & Max & 0.751 & 0.751 & 0.001 \\
\hline \multirow[t]{3}{*}{ All } & Rainfall & 0.288 & 0.288 & 0.001 \\
\hline & Min & 0.047 & 0.336 & 0.108 \\
\hline & Max & 0.065 & 0.400 & 0.053 \\
\hline
\end{tabular}




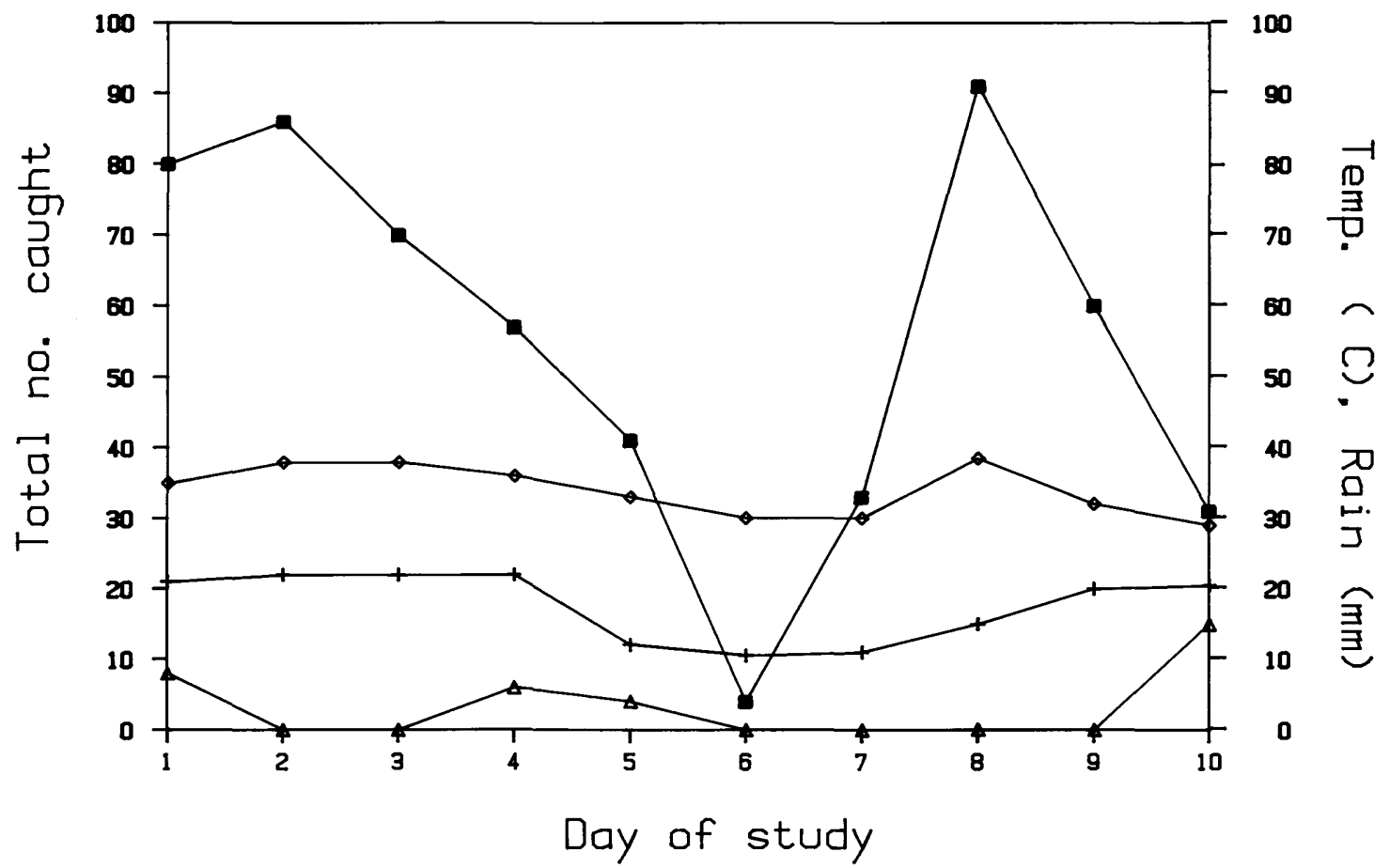

Fig. 6. Relationships of rainfall $(\triangle-\Delta)$, minimum temperature $(+-+)$, maximum temperature $(\diamond-\diamond)$, and total number of cockroaches captured (D) per day at site $\mathrm{C}$.

1985). But several evening-night examinations at site C confirmed that trees with treeholes served primarily as refuges for adult and nymphal stages rather than as perching posts.

Salient differences exist between smokybrown and $E$. floridana cockroaches in terms of focality. Treeholes or palms, or both, were abundant at sites $A$ and $C$, where smokybrown cockroaches predominated in these habitats. At site B, characterized by an abundance of noncypress mulch and an absence of treeholes and palms, $\boldsymbol{E}$. floridana predominated. Thus, for smokybrown cockroaches, focalities appear to be treeholes and palms, woodpiles, and loose mulch, in descending order of preference. For E. floridana, woodpiles, certain kinds of mulches and ground cover, and treeholes appear to be the order of preference. Alternatively, treeholes may be equally suitable for $E$. floridana as a primary habitat, but the species may be outcompeted by smokybrown cockroaches; however, this was not examined in this study.

Mizuno \& Tsuji (1974) found that smokybrown cockroaches prefer $1-\mathrm{cm}$ spaces over 2 -cm or 0.5 $\mathrm{cm}$ openings in harborage material in laboratory studies. If this is true in the field, then mulches with ample interstitial space, such as deciduous leaves, pine straw, and pine bark, should provide suitable harborage sites. My data support this contention. In contrast, mulch made from baldcypress wood pulp compresses and offers little space for these relatively large cockroaches, but it apparently provides sufficient interstices for the much smaller
C. lutea lutea. The likelihood that baldcypress contains repellent compounds in concentrations that preclude cockroach infestation seems doubtful, because several baldcypress trees with treeholes were found to be infested.

Physiological constraints of each species may provide insight as to how resources are partitioned. Water conservation is considered to be among the most important mechanisms for survival (Cornwell 1968), and probably dictates suitability of microhabitats. Appel \& Rust (1985) found that compared with many other species, smokybrown cockroaches lose body water rapidly as a result of high cuticular permeability; they concluded that relative humidity and the availability of free water were especially critical to survival of this species. Air movement also increases rates of water loss (Ramsey 1935), and environments, such as caves, with minimal air flow, high humidity, and free water, are favored by several species (reviewed in Schal et al. 1984).

Among peridomestic microhabitats, treeholes can be considered the ecological equivalent of caves (Schal et al. 1984), providing an optimal stable microclimate; whereas conditions in mulches are probably more variable and diminish long-term probabilities of survival. Although cuticular permeability of $E$. floridana has not been evaluated, this study suggests that the species may be better suited than smokybrowns to the microclimate of mulches or thick growths of ground cover (site B). Also, faster maturation of E. floridana (Willis et 
al. 1958) may permit this species to rebound from decimation attributed to the more variable microhabitat in leaf litter, thereby allowing the species to occupy this habitat successfully.

Cockroach mobility has been studied several times, and the overwhelming conclusion is that they are relatively immobile as a group, and females are recaptured more frequently than males see Schal et al. [1984] for a review). Thoms \& Robinson (1987) studied mobility of the oriental cockroach and found that $50 \%$ of recaptures had moved a mean maximal distance of only $2 \mathrm{~m}$. Other researchers studying movement of adult smokybrowns computed means of 6-9 m (Fleet et al. 1978, Appel \& Rust 1985). However, they included only those recaptures that involved movement (minimal distance between traps was $3 \mathrm{~m}$ ). Data from Texas (Appel \& Rust 1985) showed that $65 \%$ of recaptures of females and $41 \%$ of males involved no net movement. Thus, exclusion of the behavior of a substantial proportion of the population seriously overestimates typical patterns of mobility.

This study also quantified mobility of nymphs with variable results. At site A, smokybrown nymphs were more mobile than females, whereas they were less mobile than both sexes at site $C$ even though the sites had a similar ecological profile. Movement is influenced in part by population density relative to carrying capacity of principal foci (Jackson \& Maier 1955). Although carrying capacities were not measured in this study, and further discussion is largely speculative, the vastness of individual treeholes at site $\mathrm{C}$ may provide more habitat than the canopies of palms at site A. Because smokybrown populations were significantly higher at site A suggests there was greater population pressure and, consequently, greater mobility of nymphs.

Research techniques can bias mobility calculations and result in erroneous inferences. A cockroach that enters a trap is obviously restricted from further movement, but data from the continuation of ground trapping following the removal of tree traps suggest that these procedures did not drastically affect the typical behavior of peridomestic cockroaches. Therefore, the value for mean distance traveled is primarily a function of the outliers, rather than representative of the behavior of a typical cockroach ${ }^{1}$. Given that cockroaches were active on a daily basis (as evident by number captured), the vast majority either remained very close to principal foci or returned to the same location at the conclusion of an activity period. In either case, focality is maintained, and the distribution of cockroaches remains predictable. These data also show that movement is directional and support conclusions of Schal et al. (1984) and Thoms \& Robinson (1987) that calculations of circular home

For this reason analyses of mobility were conducted on ranks of recaptures pooled by species or site. This eliminates the bias that long movements have on means, and conservatively examines the trends of mobility among species and sites. ranges (Hayne 1949) do not translate to typical behavior.

Assuming that only a small, but consistent, percentage of a population typically moves further than $2 \mathrm{~m}$, the probability of a cockroach population's expanding to nearby potential habitats becomes a function of the distance from the principal foci to potential expansion foci, and the overall size of the population. Thus, estimates of population size would be useful in determining rates of expansion, the effect of winter on survivorship, or the required coverage of a control strategy. Methods of estimating populations require several assumptions, such as relatively high rates of recapture, minimal mortality during the study, and a closed population (Southwood 1978). Data from this study meet these assumptions, and the Lincoln index method appears to be acceptable, if not preferable, based on consistency of estimates (Table 9, SEM) and ease of calculation.

Although recapture rates indicate that the Schnabel census should be reliable, it is overly sensitive to the number in each recapture category, as well as to the relationship between categories. As a study progresses, numbers in each category increase, and the resultant population estimate increases sharply. This was apparent at site $C$ in comparing estimates based on cockroaches marked only on day 1 with estimates from days 1-3 (Table 8 ). Although the $r^{2}$ values are high for each, indicating a strong correlation, population estimates vary greatly. The utility of this method is dubious, unless it is restricted to a relatively narrow time frame of marking, which was not determined in this study.

The effect of meteorological phenomena on cockroach activity has been observed in general terms by several investigators, but none has examined the combined effects of temperature (high and low) and rainfall. Appel \& Rust (1985) noted a decrease in trap catches of smokybrown cockroaches in Texas following rainfall. They found that the time of rainfall, relative to onset of usual nocturnal activity, was important, but they did not correlate the quantity of rain with trap catches. Daily temperature fluctuations were minimal (July) and did not correlate with activity. Fleet et al. (1978) found that simple regression models examining the effect of low and high temperatures accounted for only 46 and $49 \%$ of the variability in trap catches at similar locales in Texas.

In this study, activity was greatest on days following rainfall and was inversely proportional to the amount of rain. Additionally, the range of temperatures during trapping over all three sites provided an unusual opportunity to assess the effect of weather on daily activity. At site A, where temperatures were highest, minimal temperatures were more predictive of activity. In contrast, at sites B and $\mathrm{C}$, where temperatures generally were cooler, maximal temperatures were more predictive. These analyses suggest that as long as minimal temper- 
atures remain above the threshold of $10.5^{\circ} \mathrm{C}$, activity of cockroaches is best correlated with the occurrence of rain (or lack of it) and the maximal daily temperature. However, when temperatures are relatively high, rainfall and minimal temperatures govern activity. During this study, relative humidity was near saturation each night, and therefore had little to no influence on activity fluctuations (Cornwell 1968).

Besides adding to our knowledge on behavioral ecology of cockroaches, this study may be useful for controlling these pests, even though this was not an objective of the research. Horsfall (1985) suggested that long-term insect suppression programs are most likely to succeed when control measures are directed toward stages of the target species that are "concentrated, immobile, and accessible." This "CIA" concept (Horsfall 1985), founded for mosquito abatement, achieves maximal control while minimizing the cost of toxicants and adverse environmental effects. Predictability in spatial distribution, activity, and mobility of peridomestic cockroaches is conducive to a strategy based on the CIA concept. Principal foci are visually recognizable and accessible, and the probability of a cockroach moving further than $2 \mathrm{~m}$ (and encountering a residual insecticide at the base of a home) is low. Thus, the population is concentrated, immobile, and accessible, and a large proportion of the population (evidenced by high recapture rates) can be intercepted before reaching the domestic environment. The attraction of cockroaches to baits suggests that the use of baited traps or toxic baits placed on trees, in woodpiles, and in areas of noncompressed mulch (especially immediately following cool weather or an afternoon rain) would affect control with a minimum of toxicant applied to the environment.

\section{Acknowledgment}

I give special thanks to property owners of sites A, B, and $\mathrm{C}$ for their cooperation in this study. Technical assistance of $\mathbf{K}$. Crosby, D. Moore, and K. Williams was invaluable in completing this work. I thank J. Hinton for identification of palms, and K. Williams for artistic assistance. I am grateful to peer reviewers P. Koehler, D. Focks, and D. Jouvenaz for helpful criticism of the manuscript.

\section{References Cited}

Appel, A. G. 1985. Aspects for the environmental physiology and behavior of the smokybrown cockroach, Periplaneta fuliginosa (Serville). Ph.D. dissertation, University of California, Riverside.

Appel, A. G. \& M. K. Rust. 1985. Outdoor activity and distribution of the smokybrown cockroach, Periplaneta fuliginosa (Dictyoptera: Blattidae). Environ. Entomol. 14: 669-673.

Beatson, S. H. \& J. S. Dripps. 1972. Long-term survival of cockroaches out of doors. Environ. Health 80: 340-341.

Brenner, R. J. \& R. S. Patterson. In press. Efficiency of a new trapping and marking technique for peridomestic cockroaches (Dictyoptera: Blattaria). J. Med. Entomol.

Conover, W. J. \& R. L. Iman. 1981. Rank transformations as a bridge between parametric and nonparametric statistics. Am. Stat. 35: 124-129.

Cornwell, P. B. 1968. The cockroach, vol. 1. Hutchinson, London.

Fleet, R. R., G. L. Piper \& G. W. Frankie. 1978. Studies on the population ecology of the smokybrown cockroach, Periplaneta fuliginosa, in a Texas outdoor urban environment. Environ. Entomol. 7: 807-814.

Hagenbuch, B. E., P. G. Koehler, R. S. Patterson \& R. J. Brenner. In press. Peridomestic cockroaches of Florida: their species composition and suppression. J. Med. Entomol.

Hayne, D. W. 1949. Calculation of size of home range J. Mammal. 30: 1-18.

Horsfall, W. R. 1985. Mosquito control in a changing world. J. Am. Mosq. Control Assoc. 1: 135-138

Jackson, W. B. \& P. P. Maier. 1955. Dispersion of marked American cockroaches from sewer manholes in Phoenix, Arizona. Am. J. Trop. Med. Hyg. 4: 141146.

Mizuno, T. \& H. Tsuji. 1974. Harbouring behavior of three species of cockroaches, Periplaneta americana, P. japonica, and Blattella germanica. Jpn. J. Sanit. Zool. 24: 237-240 (in Japanese, with English summary).

Piper, G. L. \& G. W. Frankie. 1978. Integrated management of urban cockroach populations, pp. 249 266. In G. W. Frankie \& C. S. Koehler [eds.], Perspectives in urban entomology. Academic, New York.

Ramsey, J. A. 1935. The evaporation of water from the cockroach. J. Exp. Biol. 12: 373-383.

Ripley, B. D. 1981. Spatial statistics. Wiley, New York.

SAS Institute. 1985a. SAS procedures guide, version 6 ed. SAS Institute, Cary, N.C.

1985b. SAS/STAT guide for personal computers, version 6 ed. SAS Institute, Cary, N.C.

Schal, C., J. Y. Gautier \& W. J. Bell. 1984. Behavioural ecology of cockroaches. Biol. Rev. 59: 209-254.

Southwood, T. R. E. 1978. Ecological methods. Wiley, New York.

Thoms, E. M. \& W. H. Robinson. 1987. Distribution and movement of the oriental cockroach (Orthoptera: Blattidae) around apartment buildings. Environ Entomol. 16: 731-737.

Willis, E. R., G. R. Riser \& L. M. Roth. 1958. Observations on reproduction and development in cockroaches. Ann. Entomol. Soc. Am. 51: 53-69.

Received for publication 12 June 1987; accepted 18 March 1988. 